\title{
Non-Destructive Testing for Building Diagnostics and Monitoring: Experience Achieved with Case Studies
}

\author{
Ayşe Tavukçuoğlu \\ Middle East Technical University, Faculty of Architecture, Department of Architecture, Ankara, Turkey
}

\begin{abstract}
Building inspection on site, in other words in-situ examinations of buildings is a troublesome work that necessitates the use of non-destructive investigation (NDT) techniques. One of the main concerns of non-destructive testing studies is to improve in-situ use of NDT techniques for diagnostic and monitoring studies. The quantitative infrared thermography (QIRT) and ultrasonic pulse velocity (UPV) measurements have distinct importance in that regard. The joint use of QIRT and ultrasonic testing allows in-situ evaluation and monitoring of historical structures and contemporary ones in relation to moisture, thermal, materials and structural failures while the buildings themselves remain intact. For instances, those methods are useful for detection of visible and invisible cracks, thermal bridges and damp zones in building materials, components and functional systems as well as for soundness assessment of materials and thermal performance assessment of building components. In addition, those methods are promising for moisture content analyses in materials and monitoring the success of conservation treatments or interventions in structures. The in-situ NDT studies for diagnostic purposes should start with the mapping of decay forms and scanning of building surfaces with infrared images. Quantitative analyses are shaped for data acquisition on site and at laboratory from representative sound and problem areas in structures or laboratory samples. Laboratory analyses are needed to support in-situ examinations and to establish the reference data for better interpretation of in situ data. Advances in laboratory tests using IRT and ultrasonic testing are guiding for in-situ materials investigations based on measurable parameters. The knowledge and experience on QIRT and ultrasonic testing are promising for the innovative studies on today's materials technologies, building science and conservation/maintenance practices. Such studies demand a multi-disciplinary approach that leads to bring together knowledge on materials science and building science.
\end{abstract}

\section{Introduction}

Building inspection on site, in other words in-situ examinations of buildings is a troublesome work that necessitates the use of non-destructive investigation (NDT) techniques. The quantitative infrared thermography (QIRT) and ultrasonic pulse velocity (UPV) measurements have distinct importance in that regard. One of the main concerns of those nondestructive testing methods is to improve their quantitative use on site for diagnostic and monitoring purposes. The knowledge achieved on QIRT and ultrasonic testing is presented here, mostly with a focus on case studies conducted on historical materials and structures. Those case studies are, in fact, research studies shaped to develop in-situ use of QIRT and ultrasonic testing methods for specific topics related to building inspection and monitoring as well as to discover their potentials and limitations in this regard.

\section{Infrared thermography and ultrasonic testing in the context of building diagnostics and monitoring}

In-situ NDT studies for diagnostic purposes start with field observations composed of mapping of decay forms with visual analyses and IR scanning. Quantitative analyses are shaped for data acquisition on site and at laboratory taken from representative sound and problem areas in structures or laboratory samples. Laboratory analyses are needed to support in-situ examinations and to establish the standard/reference data for better interpretation of the in-situ data.

In order to enhance the accuracy of non-destructive investigations, particularly the in-situ ones, there is necessity of using more than one NDT testing method and supporting the in-situ investigation with laboratory tests. Advances in laboratory tests using IRT and ultrasonic testing are promising to give the hints of using those methods on site for quantitative analyses, in other 
words, allow making in-situ examinations based on measurable parameters.

Infrared (IR) thermography is commonly used for detection of building defects, such as thermal bridges, air leakages or moist spots, particularly in the context of energy conservation. It measures thermal radiation emitted by the material and depicts the examined area as an image in colours corresponding to a predefined temperature scale. The application of a hot or cold source to a specific area results in the warming up or cooling down of the surface area under examination at varying rates. Final surface temperatures differ depending on the thermal properties, specifically thermal resistance and thermal inertia characteristics, of the surface and subsurface layers. For instance, entrapped moisture in a porous material increases its thermal conductivity, therefore decreases its thermal resistance and creates a kind of thermal bridge. Such a defect is visible in infrared images as cooler areas. In addition, exposure of wet surfaces to mild wind or sun increases the evaporation rate, therefore accelerates evaporative cooling. It means that heating the surfaces or wind effect may also enhance the visibility of moist areas in infrared images.

The IR scanning is useful and time-saving for the insitu check-up of the overall structure, especially with a focus on visible and invisible materials defects, moisture and thermal failures, and various materials use. However, during the in-situ examinations the quantitative analyses of the representative areas are obligatory for the correct interpretation of the problem areas detected in single IR images. Thermal monitoring of the problem area by means of sequential thermal imaging is a favourable technique for quantitative analysis of the problem area. This technique allows taking infrared images in sequences from the target area during the periods when the target area is exposed to heating and then cooling conditions as well as producing differential thermal images which show surface temperature differences between the initial and the last IR images for heating or cooling period. Due to the changes in physical and thermal properties of the defect area, the impact of any failure can easily be followed in differential images. In addition, the temperature evolution in time under heating and/or cooling exposure conditions can be examined by the graphs showing changes in surface temperature as a function of square root of time. The slope of the linear regression presents the rate of warming up $\left(\mathrm{R}_{\mathrm{W}}\right)$ or the rate of cooling down $\left(\mathrm{R}_{\mathrm{C}}\right)$ for each target area. Those rates are the measurable parameters related with the thermal inertia characteristics of materials. Thermal inertia characteristics of the problem area can also be interpreted relatively by comparing the warming up/cooling rates of problem area in reference to the rates of sound material (reference area).

In short, that investigation technique is sensitive to thermal characteristics of materials. Since thermal characteristics are very related with the physical, physicomechanical and/or mechanical properties of materials, changes in those properties can be monitored precisely by quantitative IR thermography.

Ultrasonic testing of building materials is based on measuring the travel time (transit time) of ultrasonic waves passing along a solid material through a certain distance between the transmitter and receiver. The measurable parameter of ultrasonic testing is the velocity of ultrasound waves propagating through the building material. The ultrasonic pulse velocity (UPV) of a material is related with its physical and mechanical properties as well as the state of deterioration, moisture/water content and presence of discontinuity. Any discontinuity within a material or increase in porosity is expected to increase the travel time and, consequently, decrease the pulse velocity. The UPV measurements can be made by positioning two transducers (one transmitter and one receiver) on opposite faces (direct transmission mode) or on the same surface (indirect transmission mode) of the material sample.

The UPV measurements taken in direct transmission mode $\left(\mathrm{UPV}_{\text {DIRECT }}\right)$ are used for assessing the state of deterioration of a material and non-visible failure/discontinuity at deeper layers, such as invisible cracks. The UPV measurements in indirect transmission mode $\left(\mathrm{UPV}_{\text {INDIRECT }}\right)$ provides precise data on estimating the depth of a visible crack while investigating surfaces in layers only accessible from one side. Difficulty in access to mutually-perpendicular faces of a building component limits the applicability of direct UPV measurements on site. In such a case, there is necessity to establish the reference data obtained from control samples and correlate the UPV data taken in direct and indirect transmission modes. That correlation makes it possible to interpret the in-situ UPV data correctly in reference to the control UPV data.

The combined use of infrared thermography and ultrasonic testing enhances the accuracy of the nondestructive in-situ examination, especially the studies on soundness assessment. A good correlation is determined between the state of deterioration of stone and its thermal inertia characteristics. The deteriorated stone samples present lower UPV values and faster warming up and cooling down rates than the sound ones.

Some research fields where QIRT and ultrasonic testing can be useful are summarized as follows:-

- detection of visible and invisible defects/failures in materials and structures, such as deep and surface cracks, detachments [1,2];

- detection of different materials use hidden behind the surfaces or buried within the section of building components [3];

- assessment of the state-of-deterioration of building materials and their distribution in the structure [2, 4 5];

- failures in functional systems of historic structures, such as water supply and drainage systems [6-9];

- assessment of thermal performance of structures as well as thermal and moisture failures in structures $[3$, $10,11]$;

- in-situ monitoring of the existing conditions before and after treatments, success of conservation treatments in historic structures $[2,12,13]$.

The advances in laboratory tests using QIRT are also promising to determine the thermal properties of materials and building walls while give the hints for in- 
situ QIRT investigations to assess moisture content in materials $[3,11,14,15]$.

\section{Some case studies: prominent findings and advancements}

Here, some case studies are summarized under respective subheadings with a focus on the prominent results of those studies and guiding remarks related with nondestructive building inspection.

\subsection{Soundness assessment of structural timber elements on quantitative basis}

A comprehensive study is needed for the in-situ soundness assessment of structural timber elements that involves:

- preliminary laboratory tests on control samples (deteriorated and non-deteriorated timber samples) to produce the reference data on UPV and thermal characteristics,

- field measurements taken from representative problem areas, and

- evaluation of in-situ data in reference to the control data.

Such a study was conducted on two types of structures [16-18]:

- The $19^{\text {th }}$ century traditional timber dwellings in Ankara belonging to Ottoman Period, namely Ayaş House in the town of Ayaş and Istiklal House in Istiklal district: The timber post and beams forming the timber frame wall of traditional dwellings were examined by in-situ UPV measurements taken in direct and indirect transmission modes and by sequential IR imaging during cooling conditions.

- Aslanhane Camii, $13^{\text {th }}$ century mosque, belonging to Seljuks Period: The timber pillars supporting the roof and timber ceiling of the structure were examined by in-situ UPV measurements taken in direct transmission mode and IR scanning.

Reference data established by the laboratory analyses on control timber samples were used for the precise interpretation of in-situ data.

\subsubsection{The reference data achieved at laboratory}

The old and new pine samples, visually-deteriorated and sound ones, collected from the structures were examined in terms of density, equilibrium moisture content at various RH conditions, UPV taken in direct and indirect transmission modes and warming up and cooling rates.

The UPV values of timber samples decrease at high moisture conditions [17]. This means that physicomechanical properties of timber elements weaken when they get wet (figure 1). The relationship between the UPV values and relative humidity conditions show that microclimatic data is an important input for correct interpretation of the UPV data, particularly for the in-situ ultrasonic investigations.

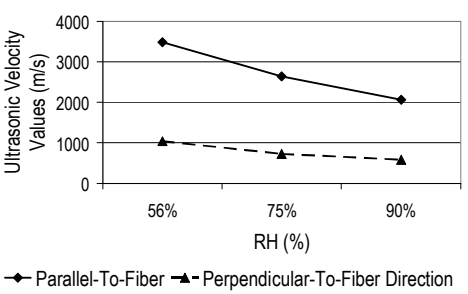

Fig. 1. Changes in ultrasonic velocity values of timber samples due to the changes in moisture content [17].

The UPV measurements exhibit the anisotropic behaviour of timber in relation to fiber direction [16-18]. The $U_{P V} V_{\text {DIRECT }}$ values parallel to fiber direction are considerably higher than (up to 3 to 3.5 times higher) the ones perpendicular to fiber direction. The UPV $\mathrm{VINDIRECT}_{\text {I }}$ values are much lower than the UPV $\mathrm{DIRECT}_{\text {values with a }}$ ratio of 0.32 in average for the measurements taken in parallel to fiber direction. Based on these relationships, the $U_{P V} V_{\text {INDIRECT }}$ values measured on site from timber surfaces in parallel to fiber direction can be used to

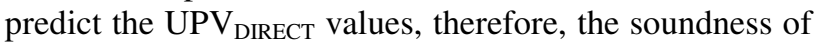
timber.

In literature, the UPV $\mathrm{DIRECT}_{\text {values for sound timber }}$ are given in the range of 1000 to $2000 \mathrm{~m} / \mathrm{s}[19,20]$. The ultrasonic data for the sound timber (control) samples measured in perpendicular-to-fiber direction correspond with the data in literature with the UPV DIRECT $_{\text {value of }}$ $1040 \mathrm{~m} / \mathrm{s}$ in average at $56 \% \mathrm{RH}$ (figure 1) $[17,18]$. The

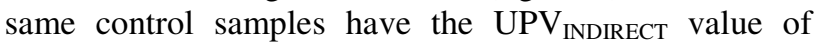
$1439 \mathrm{~m} / \mathrm{s}$ in average, measured in parallel to fiber direction [16].

When the timber deteriorates, its density decreases and its warming up/cooling rates increases. The sound pine samples (control samples) have the lowest warming up/cooling rates and the highest density, indicating their higher thermal inertia. Depending on severeness of deterioration, the visually-deteriorated pine samples warm up or cool down faster than the sound one (control sample) in the range of 1.2 and 1.7. Measuring the changes in warming up or cooling down rates of timber samples allows assessing their state of deterioration in comparison to sound (reference) samples.

\subsubsection{Evaluation of in-situ data with respect to reference data}

Some timber beams and posts in timber framed houses

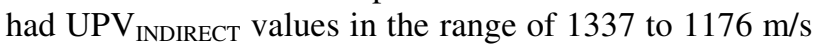
taken in parallel to fiber direction [16]. Evaluation of insitu UPV data with respect to the reference data has shown that those timber elements are still sound. That result was also confirmed with in-situ UPV DIRECT $_{\text {Th }}$ measurements taken in perpendicular to fiber direction wherever cross arrangements for the transducers could be made. Those $\mathrm{UPV}_{\text {DIRECT }}$ measurements in the range of $1400-1660 \mathrm{~m} / \mathrm{s}$ are in agreement with values given for the sound timber material in literature [19, 20]. Partial deteriorations on some parts of timber posts and beams could be detected with UPV INDIRECT $_{\text {values below the }}$ acceptable range. In short, in-situ UPV INDIRECT $_{\text {and }}$ $\mathrm{UPV}_{\text {DIRECT }}$ measurements have assured the soundness of 
structural timber elements in some parts and extensive deterioration in other parts of the structures under examination.

The sound timber elements present even surface temperature distribution in differential IR images while the deteriorated ones show heterogeneous temperature distribution (figure 2). In addition, the cooling rates of deteriorated and severely deteriorated timber post/beam were found to be 1.55 and 2.48 times faster than the cooling rate of the sound post/beam, respectively [16]. This meant that thermal inertia of deteriorated timber decreases due to decrease in density and increase in porosity.

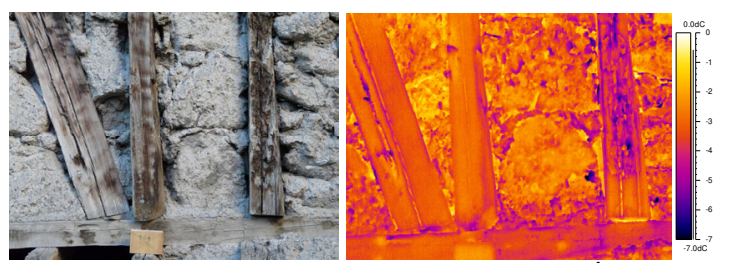

Fig. 2. Partial view from the timber frame wall of İstiklal House (at the left); the differential IR image showing the temperature difference between the initial and the last IR images during the cooling period of 603 seconds [16].

The UPV $V_{\text {DIRECT }}$ values taken in perpendicular to fiber direction from the timber pillars in Aslanhane Camii were measured in the range of 706 to $1753 \mathrm{~m} / \mathrm{s}[17,18]$. Those data falling into the reference $U_{P V} V_{\text {DIRECT }}$ values obtained for sound timber show that the timber pillars of the mosque are still sound.

\subsection{Crack depth assessment in stone masonry}

An in-situ examination on structural cracks with a focus on depth assessment was conducted on a $16^{\text {th }}$ century Ottoman mosque in Ankara, Cenabi Ahmet Paşa Camii [1]. This stone masonry structure with a brick upper structure suffers from serious cracks observed at its walls and dome due to the differential settlement of the clayey ground following the extremely dry seasons of recent years $[21,22]$.

By the study, a non-destructive investigation method was developed for the estimation of crack depth in a structure by the combined use of QIRT and ultrasonic testing [1]. The depths of cracks in accessible areas were predicted by quantitative analyses of UPV $\mathrm{INDIRECT}_{\text {data }}$ taken parallel to the stone surfaces (figure 3 ). The thermal inertia characteristics of those cracks with known depths were defined by quantitative analyses of surface temperature data. The cracks which are not accessible for ultrasonic testing were then able to be monitored by thermographic analyses to identify whether they are deep or superficial cracks.

The superficial and deep cracks have different thermal responses to exposed conditions which made them easily distinguishable by QIRT analyses (figure 4). For instances:-

- The superficial cracks associating with/neighbouring plaster detachments had thermal response similar to detached surfaces, having faster warming up and cooling down rates than the sound stone surfaces.
- The deeper cracks at masonry wall, on the other hand, presented noticeably slower warming up and cooling down rates than the sound stone surfaces.

- The deepest cracks allowing air leakage through the wall section had the coldest initial surface temperature and slightly cooled down during the heating period due to the accelerated evaporative cooling in the crack cavity.

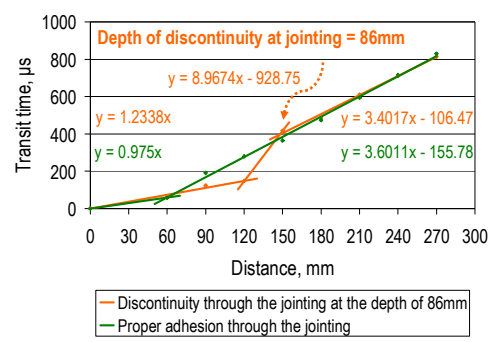

Fig. 3. The slope of regression lines for the tuff stone followed by proper jointing without any discontinuity (lines in green) and the change in the regression slope corresponding to the depth of discontinuity at jointing (lines in orange) [1].

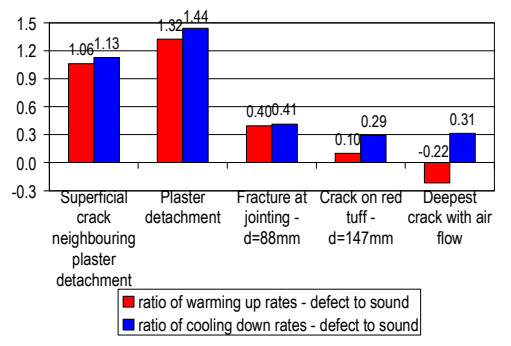

Fig. 4. The ratios of the $\mathrm{R}_{\mathrm{W}}$ (or $\mathrm{R}_{\mathrm{C}}$ ) of crack/defect to the $\mathrm{R}_{\mathrm{W}}$ (or $R_{C}$ ) of sound/reference stone surface [1].

\subsection{Identification of emergency areas that needed conservation treatments and their monitoring}

A comprehensive research involved QIRT and ultrasonic testing supported by the maps of visual decay forms and laboratory tests was conducted on Nemrut Dă̆ Monument, which is an archaeological site located in eastern Turkey in the province of Kahta- Adiyaman and positioned at the top of Nemrut Dağ at $2150 \mathrm{~m}$ altitude. The site is in the list of World Cultural Heritage since 1987. The study was focused on the in-situ examination of the limestone and sandstone statues in Nemrut Dağ Monument to assess their state of deterioration and to determine the target areas that needed urgent conservation treatments $[2,4]$.

The reference data on UPV and thermal inertia characteristics of sound and deteriorated limestone and sandstone samples were produced (figure 5). The relationship between the state of deterioration of stone surfaces and their thermal inertia characteristics was then used for the assessment of problem areas on statues surfaces. The deteriorated stone samples present lower UPV values and faster warming up $\left(\mathrm{R}_{\mathrm{W}}\right)$ and cooling down $\left(R_{C}\right)$ rates than the sound ones. In other words, the weakening in physicomechanical properties causes the thermal inertia of the deteriorated stone samples to decrease. 


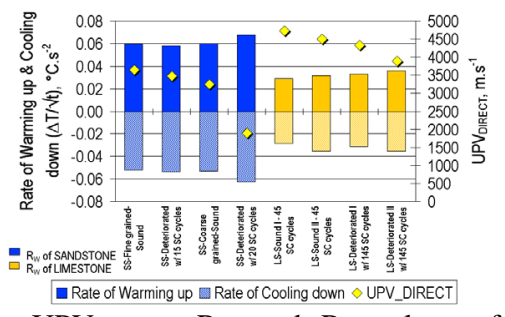

Fig. 5. The $U P V_{\text {DIRECT }}, R_{W}$ and $R_{C}$ values of sound and artificially-weathered sandstone and limestone samples showing that the deteriorated samples had lower UPV $_{\text {DIRECT }}$ and faster $\mathrm{R}_{\mathrm{W}}$ values than the sound ones [4].

The decay forms that required urgent conservation treatments are the material loss and detachment areas by fragmental disintegration in limestones and the scales detaching from the sandstones. The fragments and scales detaching from the rock body could easily be detected in differential IR images due to their fast warming up or cooling down behaviour under exposed conditions (figure $6)$. The soundness of the fragments and scales were assessed on site by UPV $_{\text {INDIRECT }}$ measurements taken from stone surfaces. Most stone fragments/scales separating from the rock body were determined to be still sound (figure 7). The deep and superficial crack patterns on limestone surfaces could be distinguished in differential IR images (figure 8). The fragments to be detached from the limestone body were mostly next to the deeper cracks belonging to a crack network. The deep and superficial cracks could not be well-distinguished in individual IR images (figure 8 - at the right middle) while the deeper cracks became visible as the warmer traces in differential IR image when sufficient heating condition was achieved on site (figure 8 - at the right bottom).

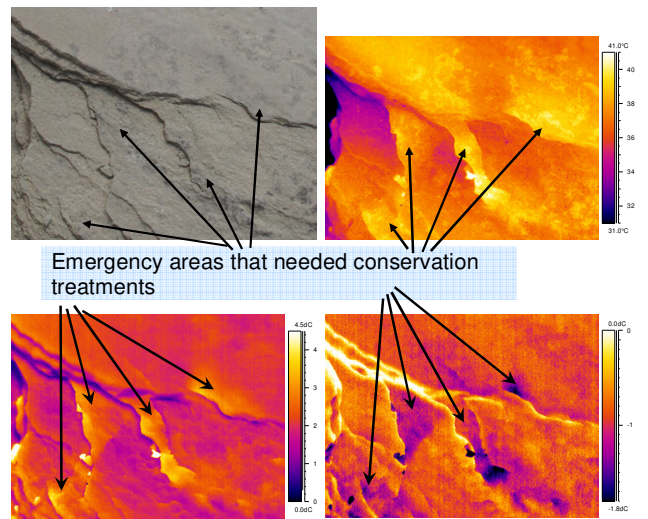

Fig. 6. The differential IR images processed for the warming up and cooling periods showing that the detaching scales on the sandstone stele warm up and cool down faster than the nondetached surfaces.
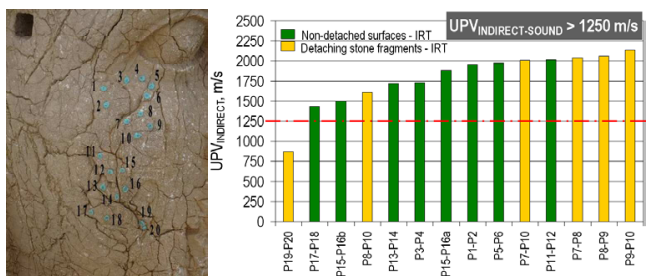

Fig. 7. Partial view showing the locations where $U_{P V} V_{\text {INDIRECT }}$ measurements were taken (at the left) and the chart showing the $\mathrm{UPV}_{\text {INDIRECT }}$ values for the non-detached sound surfaces and detaching stone fragments.

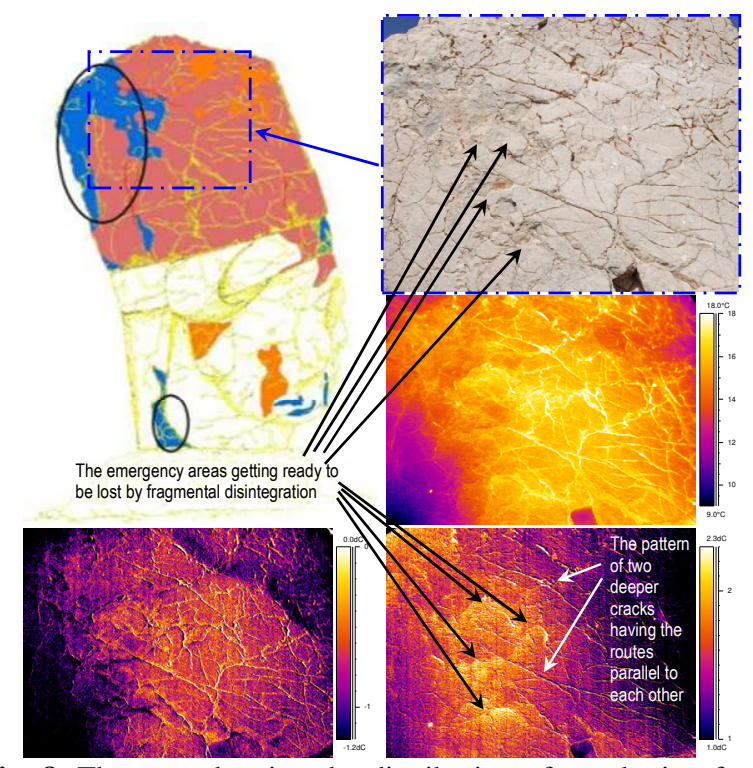

Fig. 8. The map showing the distribution of weathering forms (at the left top), the digital photo of the area under QIRT examination (at the right top), and the IR image of the selected area at the climatic conditions of $8.6^{\circ} \mathrm{C}$ and $63 \%$ (at the right middle), its differential images processed for the cooling period of 191s (at the left bottom) and heating period of 1426s (at the right bottom).

The use of QIRT and ultrasonic testing on site complemented each other to point out the emergency areas that needed conservation treatments. Those emergency areas had priority for the conservation treatments, such as for the deep cracks to be treated against water penetration, the prevention of losses due to scales or fragmental disintegration and control of decay/detaching mechanisms in the rock body.

The in-situ data obtained from the emergency areas of limestone and sandstone statues/steles before treatment have vital importance for monitoring the progress in those emergency areas after treatment in terms of $\mathrm{UPV}_{\text {INDIRECT }}$ values and warming up/cooling down rates..

\subsection{Determination of critical moisture content in porous materials - Recommendation for a standard laboratory test}

Quantitative IR Thermography (QIRT) can be used for the determination of critical moisture content $\left(\Theta_{c}\right)$ level for porous materials $[14,15]$. The weathering conditions, such as the cycles of freezing-thawing, wetting-drying and salt crystallization, are more damaging for wet porous materials when the moisture content is above the critical moisture content $\left(\Theta_{c}\right)$ [23, 24]. For in-situ diagnostic studies, it is therefore, essential to determine whether moisture content in damp zones of a structure is above or far below the $\Theta_{c}$.

A procedure based on QIRT was developed for precisely-analysing the transition stage between the saturated and dry phases of a porous material in order to determine its effective $\Theta_{c}$, as a physical property [14]. The $\Theta_{c}$ level for some building materials, such as repair brick and tuffs, were examined in laboratory by QIRT and the Standard Gravimetric Method (SGM). 
During the process of moisture desorption at certain boundary conditions, the weight loss of water-saturated brick and tuff samples together with the thermographic view of their evaporating surface were recorded with $2 \mathrm{~s}$ intervals. The data obtained were then analysed in terms of evaporation rate $\left(\mathrm{R}_{\mathrm{E}}\right)$ and a new informative parameter called Evaporative Thermal Index (ETI) (figure 9) [14]. The standard test of evaporation rate is based on the sample weight loss change in time during the drying process, knowing the evaporating area [25]. ETI is related to the surface temperature and defined as the normalized temperature difference between actual (evaporating) and reference (dry) surface [14]. Then, $\mathrm{R}_{\mathrm{E}}$ and ETI values were computed as a function of the moisture content in the sample. Both $R_{E}$ and ETI curves as a function of $\Theta$ were produced for their joint analysis in terms of knickpoint at time $t_{c}$ (time critical) when $\Theta_{c}$ has been reached (figure 9). A good correlation was achieved between the values of $\mathrm{R}_{\mathrm{E}}$ and ETI.

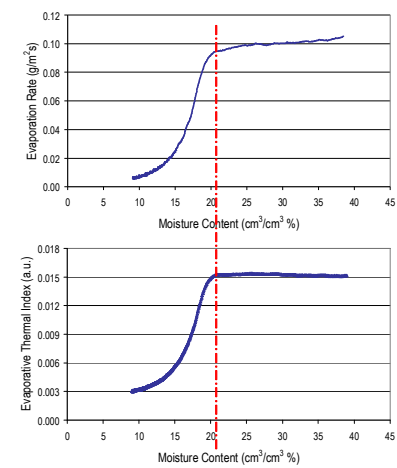

Fig. 9. A good correlation was achieved between the $R_{E}$ and ETI values: The knick-points indicating the $\theta_{c}$ for the materials are the same for both Standard Gravimetric Method and Quantitative IR Thermography.

The study exhibited that the monitoring of a wet surface during the drying process for a certain period of time by means of IR sequences is useful to decide on whether the moisture content in the material is above or below $\Theta_{c}$. In addition, the results obtained in the laboratory are promising to develop in-situ methods for quantitative determination of moisture content, only by using temperature measurements.

\subsection{Assessment of thermal transmittance value of existing building walls}

In today's constructions, the emphasis is given to the design of energy efficient buildings and improvement of existing buildings in terms of their energy efficiency. The recent studies of QIRT focus on development of standard laboratory and in-situ tests:

- to determine thermal insulation characteristics of building walls

- to identify thermal failure types,

in terms of measurable thermal parameters [3, 11].

The joint use of calibrated hot box method and IRT at laboratory conditions allowed assessment of thermal transmittance value $\left(U, \mathrm{~W} / \mathrm{m}^{2} \mathrm{~K}\right)$ of the perforated brick wall samples [11]. The experimental setup and the results achieved also gave the hints of in-situ testing methods in order to measure the real thermal transmittance value of existing building walls by thermal monitoring of wall surfaces at the cold side while inside is heated.

Considering the knowledge above, another QIRT study was carried out with a focus on in-situ thermal performance assessment of some commonly-used wall sections in terms of thermal transmittance value [3]. The infrared images were taken during winter when inside was warm while outside was cold in steady state condition. The actual thermal transmittance value $\left(\mathrm{U}_{\text {INSITU }}, \mathrm{W} / \mathrm{m}^{2} \mathrm{~K}\right)$ of existing walls were determined by using the in-situ surface temperature and microclimatic data together with relevant equations defined in the literature [26, 27]. Therefore, the QIRT methods are promising for the studies on thermal performance certification of building walls and energy efficiency rating of buildings. The common use of infrared thermography in building diagnostics, therefore, need to be encouraged.

\section{Conclusion}

The advances in NDT techniques are promising for the in-situ examinations and monitoring of historic and contemporary structures on quantitative basis. The combined use of infrared thermography and ultrasonic testing has potential for detecting the problem areas on building surfaces and monitoring the changes in thermophysical and physicomechanical properties of problem areas before and after treatments/interventions.

Ultrasonic testing, particularly the combined use of UPV measurements taken in direct and indirect transmission modes, is useful for predicting the depth of cracks at stone masonry and state of soundness/deterioration of building materials. This method can also be used for detecting non-visible failure(s) at deeper layers. However, UPV measurements on site is really demanding since data acquisition is restricted to the levels available for human body and requires long working hours at site due to the repetition of UPV measurements for several times to achieve reliable data. Therefore, its use is more reasonable for representative sampling instead of its extensive use in the structure. The QIRT survey, on the other hand, is easier and more practical method to achieve reliable and precise data in a short period of time in case that the method of data acquisition on site has been carefully-thought and well-organized beforehand. It requires long working hours at office for the quantitative analyses of the surface temperature data. Here, the selection of sensitive thermographic equipment with high image quality allows its extensive use in the structure, especially for imaging the unattainable regions.

The knowledge on the combined use of QIRT and ultrasonic testing are promising for innovative studies on today's materials technologies, building science and conservation/maintenance practices. Such innovative studies involving non-destructive investigations demand a multi-disciplinary approach that leads to bring together knowledge on materials science and building science. 


\section{References}

1. A. Tavukçuoğlu, S. Akevren, E. Grinzato, In-situ examination of structural cracks at historic masonry structures by quantitative infrared thermography and ultrasonic testing. Journal of Modern Optics, 57(18), 1779-1789 (2010).

2. A. Tavukçuoğlu, E.N. Caner-Saltık, K.G. Akoğlu, M. Isıkoğlu, E. Caner E. In-Situ Examination of Nemrut Dağ Sandstone and Limestone Statues by NDT Methods. In: Proceedings of International Conference on "Jardins De Pierrres - Conservation of stone in Parks, Gardens and Cemeteries", Paris, France, 22-24 June 2011 (pp. 204-213). France: SFIIC - Institut National du Patrimoine (2011).

3. M. Sayın, A. Tavukçuoğlu. Quantitative assessment of thermal transmittance in building walls by in-situ infrared thermography. In A. Tavil and O.C. Celik (Eds.): Interdisciplinary Perspectives for Future Building Envelopes - ICBEST 2017 International Conference on Building Envelope Systems and Technologies, 15-18 May 2017, Istanbul, Turkey (pp. 202-215). İstanbul Technical University (2017).

4. A. Tavukcuoglu, E.N. Caner-Saltik, Quantitative Infrared Thermography and Ultrasonic Testing for InSitu Assessment of Nemrut Dag Stone Statues, Atti della Fondazione Giorgio Ronchi, Vol: LXIX No :4 (459-472). Fondazione Giorgio Ronchi (2014).

5. A. Tavukçuoğlu, E.N. Caner-Saltık, F. Erol, Ö. Çetin, F. Karahan-Dağ, Non-destructive Monitoring of Salt Weathering in Dolostone. In A. Tavil and O.C. Celik (Eds.): Interdisciplinary Perspectives for Future Building Envelopes - ICBEST 2017 International Conference on Building Envelope Systems and Technologies, 15-18 May 2017, Istanbul, Turkey (pp. 242-256). İstanbul Technical University (2017).

6. A. Tavukcuoğlu, A. Düzgüneş, Ş. Demirci, Ş., E.N Caner-Saltık, The assessment of a roof drainage system for an historical building. Building and Environment, 42, 2699-2709 (2007).

7. A. Tavukcuoğlu, A. Düzgüneş, E.N. Caner-Saltık, Ş. Demirci, Use of IR thermography for the assessment of surface water drainage problems in an historical building, Ağzıkarahan (Aksaray), Turkey. NDT \& E International, 38, 402-410 (2005).

8. G. Disli, A. Tavukcuoglu, L. Tosun, E. Grinzato, The assessment of roof drainage system of a historical Turkish bath: Sengul Hammam. In: 11 DBMC International conference on Durability of Building Materials and Components, 11-14 May 2008, İstanbul, Turkey, Vol 3. (pp. 1287-1297). İstanbul, Turkey: İstanbul Technical University Press (2008).

9. G. Disli, A. Tavukcuoglu, L. Tosun, An investigation on water consumption and waste water discharge systems for historical Turkish baths. In: $8^{\text {th }}$ International HVaC-R Technology Symposium, 1214 May, 2008, Istanbul, Turkey (pp. 556-565). Turkish Society of HVAC \& Sanitary Engineers (2008).

10. A. Tavukcuoglu, A., P. Cicek, E. Grinzato, Thermal analysis of an historical Turkish bath by quantitaive
IR thermography. QIRT (Quantitative InfraRed Thermography) Journal, 5(2), 151-173 (2008).

11. R. Tuğla, A. Tavukçuoğlu, M. Arslan, Examination of thermal properties and failures of brick walls by the use of infrared thermograpy and hot box method; In: RENEWBUILD $2013-1^{\text {st }} \quad$ International conference \& exhibition on "Application of efficient \& renewable energy technologies in low cost buildings and construction, Ankara, Turkey, 16-18 September 2013 (pp. 180-199). Ankara, Turkey: Gazi University (2013).

12. F. Karahan Dağ, Ç.T. Mısır, S. Çömez, M. Erdil, A. Tavukçuoğlu, E. N. Caner-Saltık, B. A. Güney, E. Caner, Assessment of Dolomite Conservation by Treatment with Nano-Dispersive Calcium Hydroxide Solution. In J.J. Hughes, T. Howind (Eds.): Science and Art: A Future for Stone: Proceedings of the $13^{\text {th }}$ Int. Congress on the Deterioration and Conservation of Stone, Vol. 2, 6 - 10 September 2016, Paisley, Scotland (pp. 839-846). University of the West of Scotland, Paisley, Scotland (2016).

13. A. Tavukçuoğlu, E. Caner-Saltık, A. Güney, Ö. Çetin, F. Erol, F., F. Karahan Dağ, F., Assessment of Nanostructured Inorganic Consolidants Used in Stone Conservation Practice. In: XIV DBMC $-14^{\text {th }}$ International Conference on Durability of Building Materials and Components, 29-31 May 2017, Ghent, Belgium (pp. 85:1-85:12). Ghent University (2017).

14. A. Tavukcuoglu, E. Grinzato, Determination of critical moisture content in porous materials by IR thermography. Quantitative InfraRed Thermography Journal, 3(2), 231-245 (2006).

15. A. Tavukcuoglu, E. Grinzato, Determination of critical moisture content level for porous materials by quantitative IR thermography. In, J.W. Lukaszewicz, P. Niemcewicz (Eds.): Proceedings of $11^{\text {th }}$ International Congress on Deterioration and Conservation of Stone, September 15-20, 2008, Torun, Poland. Vol.1. (pp. 529-538). Poland. Nicolaus Copernicus University Press (2008).

16. A. Kandemir, Soundness assessment of historic structural timber by the use of non-destructive methods, Unpublished Ph.D dissertation, Graduate Program in Restoration, Department of Architecture, Middle East Technical University, Ankara, Turkey (2010).

17. A. Kandemir Yucel, A. Tavukcuoglu, E. N. Saltik, In situ assessment of structural timber elements of a historic building by infrared thermography and ultrasonic velocity. Infrared Physics \& Technology, 49, 243-248 (2007).

18. A. Kandemir Yucel, A. Tavukcuoglu, E. N. Saltik, Non-destructive analyses of Historic timber elements to assess their state of preservation. In F. W. Broker (Ed.), Proceedings of the $14^{\text {th }}$ International Symposium on Nondestructive Testing of Wood, Germany, May 2-4, 2005 (135-144).Germany: Shaker Verlag (2005).

19. F.C. Beall, Overview of the use of ultrasonic technologies in research on wood properties, Wood Science and Technology, 36 197-212 (2002). 
20. D.E. Bray, D. McBride, Nondestructive Testing Techniques, Canada, John Wiley \& Sons, Inc. (1992).

21. K.O. Cetin, E. Canbay, Cenabi Ahmet Pasa Camii, Temel Zeminleri Geoteknik Değerlendirme Raporu. Unpublished research report, submitted to General Pious Foundation. ODTU Doner Sermaye Protokol No: 2008.03.03.1.00.17. March 2008.

22. E. Canbay, Tetkik Raporu - Cenabi Ahmet Paşa Camii Değerlendirme Raporu. Unpublished research report, submitted to General Pious Foundation. April 2008.

23. H. Garrecht. Corrosion of Building Materials Caused by Microclimatic and Weathering Attack. In C. Sjöström (Ed.), Durability of Building Materials and Components 7, Vol.1. pp.150-159. London: E. \& FN Spon (1996)

24. G. Massari, M. Massari Damp buildings, old and new. Rome: ICCROM (1993).

25. RILEM, "Tentative Recommendations, Commission - 25 - PEM, Recommended tests to measure the deterioration of stone and to assess the effectiveness of treatment methods", Materiaux and Construction, 13, pp.173-253 (1980).

26. R. Albatici, A. M. Tonelli, Infrared thermovision technique for the assessment of thermal transmittance value of opaque building elements on site. Energy and Buildings, 42(11), 2177-2183. (2010).

27. R. Albatici, R., A. M. Tonelli, M. Chiogna. A comprehensive experimental approach for the validation of quantitative infrared thermography in the evaluation of building thermal transmittance. Applied Energy, 141, 218-228 (2015). 